\title{
Sowing the seeds of science
}

\author{
Encouraging researchers to become activists and engage with the public to combat the rising tide of \\ scientific mistrust is easier said than done. Harder still will be to better enable PhDs to thrive in careers away \\ from science, in the public and private sectors, but doing so could bear substantial fruit in the long-term.
}

With the political landscape changing in various parts of the world, seemingly towards one in which evidence-based policy and the value of expertise will be diminished in favour of populist policies and short-termism, there is growing reason to be concerned about scientific ignorance among the general public. Recent calls for researchers to turn to activism (Nat. Ecol. Evol. 1, 0042; 2017) and increase engagement with citizens through social media (Nature 541, 5; 2017) are therefore understandable. Social media is a powerful tool for the rapid dissemination of information; breaking news will often have been thrice round the Twittersphere before it appears in mainstream news outlets. Speed is not always a blessing though, and information that is incorrect (whether accidentally or deliberately so) will spread just as speedily. Social media tends to be built on connections between individuals that are (at least in part) like-minded, resulting in networks that can be all but closed to outsiders and their views - the so-called bubble or echo-chamber effect that is, in part, responsible for the failure of most to foresee the recent victories for President Donald Trump and the Leave campaign in the UK Brexit referendum. In those corners where engagement between individuals with opposing views does occur, the discourse can rapidly descend into incivility, not only shutting down the opportunity for productive debate but also the likelihood of others engaging in discussion in the future. Add increasing populism; false balance; science denial; fictional 'news'; and the low levels of scientific literacy in the general public, our political classes, business and the media into the mix, and it is perhaps no surprise that the nuanced and considered advice of scientists, which is based on the best evidence to hand, is often not heeded. So yes, researchers should be encouraged to engage more, especially outside of any bubble in which they find themselves, but whether this alone will be sufficient is unclear, and if it is not, then what else can be done?

One route may be to mobilize those who have received advanced scientific training (PhD students and postdocs), but do not necessarily desire to continue in academic or industrial research, to forge new careers in entirely different employment sectors. $\mathrm{PhDs}$ are highly valued by employers in the research and development and manufacturing and engineering sectors, as well as by those whose businesses are built around technology or analysis. With $\mathrm{PhD}$ students gaining experience in managing a research project, as well as desirable technical and analytical skills, this is perhaps unsurprising. But what of other employment sectors that are fundamental to shaping society, such as government, finance, law, business, education and media? In the UK, among the 650 members of parliament that entered the house after the 2015 general election, only 1 had a $\mathrm{PhD}$ in a science, technology, engineering and mathematics (STEM) subject, while in the US there are currently no senators and only 2 representatives with STEM $\mathrm{PhDs}$, out of a pool of 535 individuals. Of the chief executive officers of the FTSE 100 companies, only 3 have PhDs. These are certainly disappointingly low numbers, but rather than being viewed as a depressing window into the perceived value of scientific training in the wider world, we could choose to see it as a challenge, a base on which to build.

Providing PhD students (and postdocs) with support to acquire the skills and experience necessary for success in sectors other than research will help to sow the seeds of scientific literacy far wider. Most academic research is carried out at institutions that also offer courses in a wide range of fields, including economics, politics, business management, marketing and creative writing. For those $\mathrm{PhD}$ graduates looking to change their career direction, creating opportunities to receive training in such areas will help them to better understand the language, knowledge and skill set needed in the new sector, and to prepare themselves to meet the challenges ahead. Institutions not already doing so should consider establishing systems whereby after graduation, $\mathrm{PhD}$ students leaving the academic research path could opt to undertake a semester (or more) in which they get access to courses in other topics, for free or at a discounted rate. Conversely, students in these fields should be encouraged to spend some time in a research laboratory, learning the basics and picking up knowledge of the scientific method and analytical rigor. Using the collective expertise of our university faculties to prepare our $\mathrm{PhD}$ students in this way is likely to be an investment that will only see a return in the long-term, once the paths from scientific training into other sectors have been better paved, and a generation of scientifically literate former researchers have infiltrated the systems and worked their way into positions of influence.

As scientists, by all means we encourage you to engage more with the wider world, but please also support colleagues who may not share your career goals to take what has been learned and use it to benefit another field. Don't treat them as though they have failed in any way; these days, being a tenured professor is the alternative career for the overwhelming majority of students undertaking postgraduate education. And if you are one of those $\mathrm{PhD}$ students deliberating how to make your future happen, we encourage you to broaden your horizons beyond the traditional sectors into which researchers are normally channelled. A career in business, the media, finance or government (or pretty much anywhere else) can be every bit as intellectually and financially rewarding as being a researcher. Don't forget what you have learned though, and during those moments in your future roles in which it can really count, be sure to bring your scientific understanding and knowledge to bear.

Imagine a future in which the choice for where to place your vote in the next election includes candidates whose previous careers were as a neuroscientist, a particle physicist or a chemist. Where the news anchor you share your evening with used to be a microbiologist and covers not the latest celebrity concoction but rather tackles tough topics and seeks truly expert opinion. Where the captains of industry used to be lieutenants of the laboratory, and where advertising executives sell using science and not sex. Imagine it, and then make it happen. 